\title{
GAMONEDA. LECTURA DE SUBLEVACIÓN INMÓVIL
}

Julia BARELLA

Universidad de Alcalá

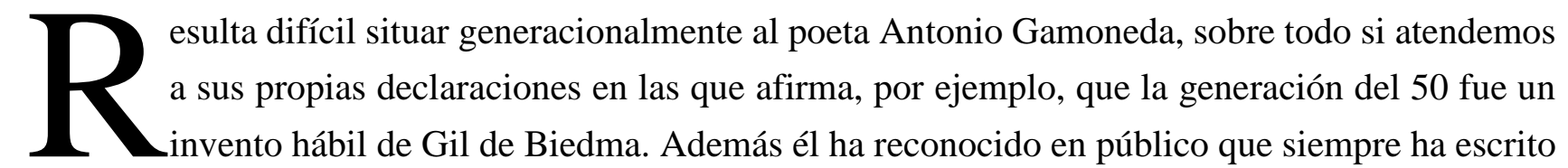
apartado de los círculos literarios, pues la poesía es «un asunto que se resuelve en soledad».

En el caso de poetas como Juan Eduardo Cirlot, Julia Uceda, Antonio Gamoneda, Chantal Maillard, Pedro Casariego y tantos otros, el propósito clasificador no solo no es necesario, sino que además es imposible. A pesar de críticos y profesores, de editores o directores de colecciones de poesía, y de los antólogos, que tanto hemos disfrutado colocando a los escritores en casillas divididas por la edad, el sexo o el lugar de nacimiento, simplificando así el trabajo; hay poetas que se resisten a las clasificaciones y que brillan en nuestra historia de la literatura como islas con luz propia.

Los primeros poemas, recogidos en Sublevación inmóvil (escritos entre 1953 y 1959¹), sí podemos situarlos, a pesar de ir dando algún que otro bandazo, entre las dos tendencias literarias que protagonizaban entonces el ambiente cultural que rodeaba al poeta en la ciudad de León. Por un lado, vislumbramos el estilo existencialista y la temática de crítica social tan del gusto de la revista Espadaña, en la que Gamoneda ha colaborado (la revista desaparece en 1951); y por otro lado, un estilo inclinado hacia la belleza, el formalismo y el culturalismo, que pocos años después caracterizará a la otra revista leonesa, Claraboya (que empieza su andadura en 1963).

Nos puede servir de ejemplo el final del poema «Sublevación», tal cual aparece en Edad. Poesía 1947-1986:

$$
\begin{aligned}
& \text { [...] Solicito } \\
& \text { una sublevación } \\
& \text { de paz, una tormenta } \\
& \text { inmóvil. Quiero, pido } \\
& \text { que la belleza sea } \\
& \text { fuerza y pan, alimento } \\
& \text { y residencia del dolor. } \\
& \text { Un mismo canto pide }
\end{aligned}
$$

\footnotetext{
${ }^{1}$ El libro se publicó en Madrid, Rialp, 1960; los poemas se integraron en Edad. Poesía 1947-1986, 1987, y algunos fueron reescritos y nuevamente publicados en Esta luz. Poesía reunida (1947-2004), 2004.
} 


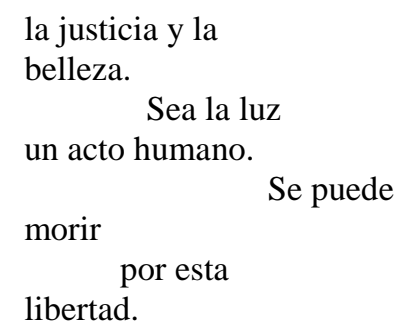

Es interesante constatar la transformación, revisión o reescritura a la que Gamoneda somete este largo poema, años después, al incluirlo en Esta luz, convirtiéndole en el que más abajo transcribimos:

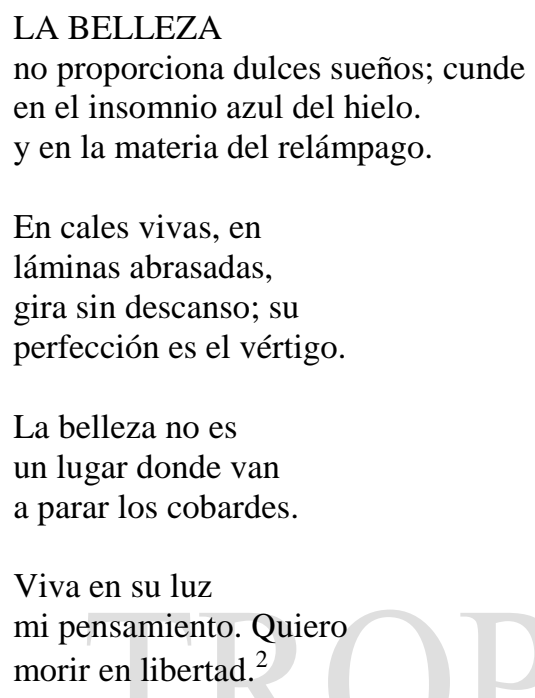

De ejemplo contrario nos serviría el comienzo del poema «Incandescencia y ruinas», que citamos en su primera versión de Sublevación inmóvil:

\section{I}

Yo invoco la cabeza más sagrada que exista debajo de la nieve.

Mi corazón azul canta purificado por el silencio.

\section{II}

Vándalo de pureza, hostígame. Si hablas, yo bajaré mis labios hasta el agua salvaje. De aquella gruta donde abrasa la frescura, ha de surgir un rey sucio de profecías [...]

Pero una excesiva inclinación a la belleza como solución escapista nunca ha sido suficiente para un poeta que espera algo más de la poesía, que cree en el poder que esta tiene para abrir nuevas rutas al conocimiento y para promover los procesos de desvelamiento y de reconocimiento de otras

${ }^{2}$ Ibid., 49. 
realidades. En el concepto de belleza gamonediano encontramos resonancias neoplatónicas y un ponderado equilibrio entre dolor y placer, equilibrio que solo se mantendrá si esa belleza (poesía) es capaz de generar el conocimiento de ese mundo que ella misma a través del lenguaje poético ha creado. La poesía será capaz, en definitiva, de generar en el ser humano una sabiduría que mitigará el dolor que implica vivir y saber que vamos a morir:

La poesía intensifica mi vida y yo vivo esta intensificación como una forma de placer. Esta intensificación y este placer son independientes de la significación: la poesía fundamentada en el sufrimiento genera también placer. ${ }^{3}$

Lo que más me llama la atención de los poemas de Sublevación inmóvil es esa voz tan personal, que vamos a volver a encontrar una y otra vez en la poesía de Gamoneda, esa potente y torrencial voz llena de sabiduría con ecos místicos que parece hablarnos de realidades que están más allá de una primera visión; esa voz capaz, también, de nombrar, desde la perspectiva de la muerte, el paisaje exterior al poeta y, al tiempo, convertir el poder simbólico de sus elementos: el frío, la nieve, el blanco silencioso del invierno, etc., en fuentes de inspiración de su pensamiento poético, e incluso de conseguir que esos elementos acaben integrándose de forma natural en el paisaje interior del poeta. No olvidemos que la poesía de Gamoneda es una poesía en gran medida autobiográfica, y que los espacios y circunstancias de las que hablan o a los que se refieren los poemas pertenecen a su realidad cotidiana:

Yo vivo en una localidad y en una provincia fría y, por tanto, como circunstancia, como componente del mundo sensible que me rodea, la nieve tiene una presencia fuerte en León; por tanto, no es extraño que si, como decía antes, mi escritura es fundamentalmente o quizá únicamente autobiográfica, ese contexto natural te viene dado también por la nieve. Y a la nieve le ocurre lo mismo que al agua (escribí por entonces uno de mis poemas más físicos, "Siento el agua") porque a fin de cuentas es agua en estado sólido con unas virtudes visuales y de otros órdenes característicos. Y aparece la proyección simbólica de la nieve, el entendimiento de la nieve como el frío pre ambular de la muerte. ${ }^{4}$

No me sorprendió la contestación que daba, en una de las múltiples entrevistas que aparecen publicadas en Internet, a la pregunta del entrevistador:

Gamoneda, confiese cuál es su poemario de cabecera. Mil gracias!!!!

Me hace usted pensar seriamente porque quizá mi poemario de cabecera son varios, varios libros. Pero si de todos ellos tuviese que elegir uno, lo que usted me pide, creo que sería la Biblia, el Antiguo Testamento. ${ }^{5}$

Los textos bíblicos eran también citados en el discurso pronunciado al recibir el Premio Cervantes $2006^{6}$. Pero, entonces, tras situar sus preferencias como lector «a partir de Garcilaso», el barroco y «las impregnaciones de Góngora», y tener que dar «un gran salto» hasta algunos poetas «de la que llaman generación del 27» (situando a Federico García Lorca «por encima de los demás»), citaba

\footnotetext{
${ }^{3}$ A. Gamoneda (1997), El cuerpo de los símbolos, 24.

${ }^{4}$ Estas declaraciones las hace en la entrevista que le hace Antón Castro y que publica el Suplemento cultural del Heraldo de Aragón (10/08/2008), que este dirige. También en http://antoncastro.blogia.com/temas/entrevistas.php (31/08/2008).

${ }^{5}$ Revista Literaria AZUL@RTE: Antonio Gamoneda/Entrevista (dimanche 11 février 2007).

${ }^{6}$ En ese momento, Gamoneda no sólo mencionaba sus preferencias como lector, también hablaba de la influencia de la música, del jazz de Nueva Orleans, por ejemplo. El discurso íntegro puede leerse en www.uah.es/universidad/premio.../ discurso_gamoneda.pdf.
} 
el Antiguo Testamento en relación con San Juan de la Cruz, haciendo hincapié en el modo «alucinado» de lectura de este:

Juan de Yepes era hijo de unos muy humildes tejedores y, socialmente, un villano. Torpe en los oficios, parece que fue hábil -le adiestraría la caridad- en el cuidado de los sifilíticos. Sufrió hambre, cárcel y torturas, y padeció el temor a la Inquisición. Sí estudió, brevemente, latín y filosofía, pero su saber más real surge de la lectura alucinada ${ }^{7}$ del Antiguo Testamento, en particular del Libro de Job y del Cantar de los cantares, así como del conocimiento, incompleto e igualmente alucinado, de la mística sufí.

Parece identificarse con esa lectura «alucinada» de la que el santo recibe su sabiduría «más real», por lo que citar el «Libro de Job» es, especialmente, significativo. Recordemos unos versos del «Libro de Job» en el que se planteaba el origen de la sabiduría de la siguiente manera:

Mas la sabiduría, ¿de dónde viene?

¿cuál es la sede de la inteligencia?

Ignora el hombre su sendero,

no se le encuentra en la tierra de los vivos.

Dice el abismo: "No está en mí".

Y el mar: "No está conmigo"

[...]

Solo Dios su camino ha distinguido,

solo él conoce su lugar.

(Porque él otea hasta los confines de la Tierra,

y ve cuanto hay bajo los cielos.)

Cuando dio peso al viento

y aforó las aguas con un módulo,

cuando a la lluvia impuso ley

y un camino a los giros de los truenos,

entonces la vio y le puso precio,

la estableció y la escudriñó.

Y dijo al hombre:

"Mira, el temor del Señor es la Sabiduría,

huir del mal, la Inteligencia.'

Libro de Job, XXVIII,12-28

Los textos bíblicos estaban presentes en la primera redacción de los versos de Sublevación inmóvil, como vimos en el poema citado «Incandescencia inmóvil», y se mantenían en la reescritura de esos poemas en Esta luz. Así, por ejemplo, leemos este mismo poema, despojado de título y esencializado:

\footnotetext{
Una cabeza piensa debajo de la nieve.

De aquella gruta donde abrasa la frescura, veo surgir a un dios sucio de profecías.

Desgarra la pureza con sus manos. Después entra en mi corazón.
}

\footnotetext{
${ }^{7}$ El subrayado es mío.
} 


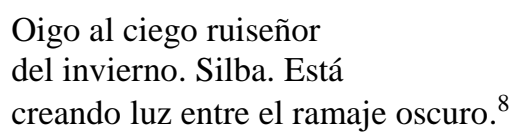

Un cierto tono apocalíptico parece dictar muchos de los versos de visiones alucinadas que encontramos dispersas por todos sus libros. Podemos entender por apocalipsis una composición literaria en la que se exponen especulaciones de carácter adivinatorio reveladas mediante el sueño o la meditación, especulaciones que también pueden proceder de visiones o alucinaciones y que van encaminadas a la comprensión de realidades ocultas a los ojos. Un apocalipsis, en este sentido, supondría una revelación sobre la naturaleza del mundo o el destino del hombre.

En Descripción de la mentira, por ejemplo, encontramos versos en los que el poeta, en primer lugar, nos describe aquello que «se escucha»: el sonido de la lenta rendición de los huesos, de la pobreza, del cansancio y la vejez, camino de la muerte. Próximo a Quevedo, nos dice que «el conjunto de mi poesía no es otra cosa que el relato de cómo voy hacia la muerte» ${ }^{9}$, y en una frase que se ha hecho célebre y se repite en sus entrevistas y en los libros de citas que aparecen en internet: «la poesía existe porque sabemos que vamos a morir».

En los versos que inician Descripción de la mentira el poeta se afana, como dijimos, en describir lo que se «escucha»:

Escuché la rendición de mis huesos depositándose en el descanso; escuché la huida de los insectos y la retracción de la sombra al ingresar en los que quedaba de mí; escuché hasta que la verdad dejó de existir en el espacio y en mi espíritu, y no pude resistir la perfección del silencio. ${ }^{10}$

Para pasar, más adelante y, en segundo lugar, a enumerar aquello que empieza a «verse»:

Vi la muerte rodeada de árboles (arboles más esbeltos que el llanto de tus hermanas), urces en el fulgor y la serenidad.

Vi sombra azul distribuida en sernas, solo advertida por animales tan antiguos como mi corazón, por emisarios muy cansados. ${ }^{11}$

Asimismo, en Arden las pérdidas, la voz del poeta de los primeros años sigue presente y parece tener un conocimiento mayor de las cosas, una percepción más profunda de la vida y del paso del tiempo, conocimiento que ha ido adquiriendo desde esa perspectiva de la muerte de la que partieron las primeras visiones y a la que se dirigen las últimas. Tanto el ritmo del verso como la insistente repetición del verbo en primera persona siguen recordando al lector el «Apocalipsis».

Vi lavandas sumergidas en un cuenco de llanto y la visión ardió en mí. Más allá de la lluvia vi serpientes enfermas -bellas en su úlceras transparentes-, frutos amenazas por espinas y sombras, hierbas excitadas por el rocío. Vi un ruiseñor agonizante y su garganta llena de luz.

$[\ldots]$

Vi descender llamas doradas sobre muros de sombra. Esto fue antes de la aparición de los símbolos.

\footnotetext{
${ }^{8}$ Esta luz, op.cit., 47.

${ }^{9}$ A. Gamoneda, El cuerpo de los símbolos, op. cit., 25.

${ }^{10}$ Cito por Esta luz, op. cit., 173.

${ }^{11}$ Ibid., 201.
} 
$[\ldots]$

Vi la pobreza a través del olvido y vi también, una sola vez, el rostro de mi madre sonriendo sobre el algodón y el acero. Una sola vez.

$[\ldots]$

Vi una tempestad conducida por lamentos, flores endurecidas en su propia belleza y, en los desvanes, augurios sobre excrementos de palomas.

$[\ldots]$

Por fin,

vi las huellas de los animales concebidos en el llanto y las agujas que atraviesan los sueños.

He despertado. Ya

no veo más que las delicadas espátulas, tan útiles en la preparación de la agonía. ${ }^{12}$

En estos poemas seguimos oyendo los ritmos bíblicos, hay algo que suena a texto sagrado y, también, un cierto talante hermético que discurre entre lo real y lo que solo desvela el poema. Gamoneda contesta de la siguiente manera a la pregunta que le hace Antón Castro:

¿En qué medida la poesía ha sido para usted adivinación, presagio?

Paul Valéry decía que el primer verso nos lo regalan los dioses. Es una manera irónica e inteligente de decir que el primer verso, y seguramente todos los que le siguen, son ajenos a cualquier proyecto, a la premeditación, a un diseño. El primer verso, y la poesía, es una especie de aparición. Aparece en ti. El pensamiento no es otra cosa que lenguaje, lenguaje íntimo, lenguaje interior. De repente en tu pensamiento aparecen palabras que están dotadas de una rítmica, es muy posible que sea ya la iniciación del poema. ${ }^{13}$

Muchas de estas enumeraciones de visiones provienen de una actitud de contemplación atenta y activa del paisaje; en general de un paisaje espacialmente conocido (paisaje leonés) y temporalmente circunscrito al invierno, como en este poema de Blues castellano (1961-1966 y 2004) ${ }^{14}$ :

\section{INVIERNO}

La nieve cruje como pan caliente

y la luz es limpia como la mirada de algunos seres humanos,

y yo pienso en el pan y en las miradas

mientras camino sobre la nieve.

Hoy es domingo y me parece

que la mañana no está únicamente sobre la tierra

sino que ha entrado suavemente en mi vida.

Yo veo el río como acero oscuro

bajar entre la nieve.

Veo el espino: llamear el rojo,

agrio fruto de enero.

Y el robledal, sobre tierra quemada,

resistir en silencio.

Hoy, domingo, la tierra es semejante

a la belleza y la necesidad

de lo que yo más amo.

\footnotetext{
${ }^{12}$ Ibid., 461, 468-469, 473-474.

${ }^{13}$ La entrevista, hecha por Antón Castro, se puede encontrar en http://antoncastro.blogia.com/temas/entrevistas.php (31/08/2008). Se publicó en el suplemento cultural del Heraldo de Aragón (10/08/2008).

${ }^{14}$ Cito por Esta luz, op.cit., 127.
} 
La influencia del San Juan de la Cruz que siempre ha estado presente, como en el discurso al recibir el Premio Cervantes citado, radica sobre todo en la actitud contemplativa ante la naturaleza y en esa lectura simbólica de la misma. Actitud contemplativa pero no integrada en el quietismo o el ensimismamiento de algunos textos de nuestros poetas místicos, los poemas de Gamoneda en los que se refiere al paisaje natural que le rodea están escritos, como él mismo dice, siguiendo el ritmo del caminante:

La andadura, y hasta podría decir por qué, es la creación de una circunstancia en la cual tu pensamiento puede dar ese pensamiento poético. Lo que pasa es que ahora tengo problemas de osamenta que no me dejan andar todo lo que quisiera y tengo que aprender a andar más bien sentado. Es muy importante sobre todo para el poeta, porque el paso crea una rítmica. La rítmica del paso se incorpora a la sensibilidad del poeta y de alguna manera termina estando presente en la escritura también. ${ }^{15}$

La actitud contemplativa hacia el paisaje va en aumento con los años, también la sabia lectura simbólica de los elementos que la componen. Gamoneda parece ir acercándose más a sí mismo a medida que contempla y conoce la naturaleza que le rodea, su historia y la de sus gentes; sus versos van describiendo y, al tiempo, dibujando el mapa de los sentimientos de la tierra que le rodea y al tiempo el de los suyos propios.

UN BOSQUE se abre en la memoria y el olor a resina es útil al corazón [...]

ESTA CASA estuvo dedicada a la labranza y la muerte.

En su interior cunden las ortigas, pesan las flores sobre las maderas atormentadas por la lluvia.

EL CUERPO esplende en el zaguán profundo, ante la trenza del esparto y los armarios destinados a los membrillos y las sombras.

De pronto, el llanto enciende los establos.

Una vecina lava la ropa fúnebre y sus brazos son blancos entre la noche y el agua. ${ }^{16}$

Estamos ante una poesía escrita desde la perspectiva de la muerte que se abre a nuevos horizontes de un conocimiento directo y profundo de la realidad del poeta; no deja de ser autobiográfica, pues en la proximidad de lo que describe está la profundidad del propio discurso.

\section{Referencias bibliográficas}

GAMONEDA, Antonio, Sublevación inmóvil, Madrid, Rialp, 1960.

—, Edad. Poesía 1947-1986, Madrid, Cátedra, 1987.

— El cuerpo de los símbolos, Madrid, Huerga y Fierro, 1997.

— Esta luz. Poesía reunida (1947-2004), Barcelona, Galaxia Gutenberg-Círculo de Lectores, 2004.

\footnotetext{
${ }^{15}$ Véase la entrevista citada de Antón Castro.

${ }^{16}$ Los versos pertenecen a «Geórgicas» en Libro del frío (1992). Cito por Esta luz, op. cit., 310-312.
} 